\title{
DISTÚRBIOS PSÍQUICOS NA NEUROCISTICERCOSE EM CRIANÇAS
}

\author{
ANTONio B. LefÈvRE * \\ ARoN J. Diament ** \\ MARIA I. VALENTE **
}

A neurocisticercose tem sido objeto de numerosos trabalhos por parte de escola neurológica de São Paulo (Brasil). Aspectos clínicos (Brotto, 1947; Canelas, 1962), cirúrgicos (Forjaz e Martinez, 1961; Almeida e col., 1966), formas menos comuns (Canelas e col., 1962 e 1963), aspectos psiquiátricos (Silveira e col., 1960), aspectos liquóricos (Spina-França, 1961 e 1962), aspectos eletroforéticos (Spina-França, 1960), aspectos eletrencefalográficos (Longo e col., 1959) e aspectos terapêuticos (Caetano Silva Jr., 1951) foram estudados de tal maneira, que hoje já se acumulou grande experiência nos diversos setores em que pode ser estudada esta neuroparasitose.

A análise da casustica de neurocisticercose do Departamento de Neurologia da Faculdade de Medicina da Universidade de São Paulo, revela eievada incidência na primeira década, demonstrando que as crianças também pagam elevado tributo ao subdesenvolvimento, conforme sentencia Canelas (1962) ao verificar que $19,6 \%$ (54 casos) dos pacientes estudados neste Departamento tinham menos de 10 anos de idade. O presente trabalho visa a apresentar as observações clínicas de 6 crianças. do sexo feminino, com 6 a 9 anos de idade, selecionadas do referido grupo de 54 casos observados na primeira década. Estas crianças apresentavam sérios distúrbios na esfera psiquica, com características especiais, uma vez que seu quadro mental era diverso daquêle freqüentemente observado nesta parasitose, ou seja, uma decadência mental global.

\section{A S U I S T I C A}

CASo 1 - V.C.P., 8 anos de idade, sexo feminino, branca, procedente de Araguari, Minas Gerais, internada em 6-9-1968 (R.G. 527.806). Em setembro de 1957 a paciente começou a apresentar cefaléias e convulsões adversivas no hemicorpo direito. As crises foram se tornando progressivamente mais frequientes e sua localização variada: eram clônicas, atingindo ora o hemicorpo direito, ora o esquerdo, ou então ambos os lados; concomitantemente, passou a ter deficit de visão assi-

Trabalho apresentado ao $\mathrm{V}$ Congresso Latinoamericano de Psiquiatria (Bogotá, Colmbia, 24 a 30 Novembro 1968).

* Professor de Clínica Neurológica Infantil, Faculdade de Medicina da Universidade de São Paulo; ** Assistentes. 
métrico e, ao ser internada, apresentava amaurose em OD. Antecedentes - Nada digno de nota; sem teníase pessoal ou familiar. Exame clinico-neurológico - Nenhum distúrbio ou sintoma neurológico. o exame oftalmoscópico mostrou área esbranquiçada no setor nasal superior da retina direita, sugerindo a presença de cisticerco intra-ocular; no ôlho esquerdo havia papiledema de 2 dioptrias. Exames subsidiários - Radiografias do crânio: sinais de hipertensão intracraniana (H.I.C.); ausência de calcificações. Eletrencefalograma: anormalidade difusa contínua, por ondas 2,5 a $4 \mathrm{c} / \mathrm{s}$ (delta), de amplitude elevada, predominando à esquerda, principalmente na região frontal, onde também se evidenciaram ondas "sharp" intercaladas com ondas lentas. Reação de Weinberg no sangue: negativa. Exames do liqüido céfalorraqueano (L.C.R.) - Em 21-8-1968: Punção sub-occipital; líqüido límpido e incolor; 53 células por $\mathrm{mm}^{3}$ (80\% linfócitos, $10 \%$ monócitos, $5 \%$ neutrófilos, $5 \%$ eosinófilos); $74 \mathrm{mg} \%$ de proteínas totais; reações de Pandy e NonneApelt fortemente positivas; reação do benjoim coloidal: 12222.22221.00000.0; reação de Takata-Ara fortemente positiva, tipo floculante; reaçoes de Wassermann e de Steinfeld negativas; reação de Weinberg fortemente positiva com 1,0 ml. Durante o período em que a paciente estêve internada foram feitos 5 outros exames de L.C.R., com resultados prảticamente idênticos.

Evolução - A paciente ficou internada durante 3 meses, durante os quais foi medicada com anti-convulsivos e sulfamidas, tendo tido alta em 30-12-1958. Dez. dias após foi reinternada por ter apresentado crises de agitação psicomotora, cefaléias frequientes e intensas e alucinações visuais caracterizadas por zoopsias. Tratada com anticonvulsivos, corticosteróides (Omcilon), antiedematosos (Diamox) e sulfamidas (Gantrisin e Sulfadiazina), Melhorou e teve alta em 11-2-1958, sem queixas, apresentando apenas a amaurose em $\mathrm{OD}$. Não voltou para contrôle de ambulatório.

Caso 2 - V. L. M., 7 anos de idade, sexo feminino, parda, procedente de Marília, São Paulo, internada em 10-10-1958 (R.G. 516.943). Em maio de 1958 apresentou quadro agudo caracterizado por tonturas, náuseas e, logo em seguida, deficit de visão em OE. No terceiro dia teve convulsão com caracteristicas não especificadas. Desde agôsto de 1958 passou a ter crises de agitação psicomotora mal caracterizadas, acompanhadas de alucinaçōes visuais em que via animais e pessoas estranhas, o que a deixava apavorada. A contactuação foi se reduzindo parcial e progressivamente; houve também redução progressiva da acuidade visual, maior à esquerda, até a cegueira, em outubro de 1958. Antecedentes - Nada digno de nota; sem teníase pessoal ou familiar. Exame clinico-neurológico - Agitação psicomotora com hipercinesias mal caracterizadas; incoordenação estático-cinética; preensão reflexa nas mãos; succão reflexa, com voracidade; edema discreto e bilateral das papilas. Exames subsidiários - Radiografias do crânio: sinais de H.I.C.; sem calcificações. Eletrencefalograma: anormalidade difusa contínua, por ondas delta de amplitude elevada $(1,5$ a $3 \mathrm{c} / \mathrm{s})$. Reação de Weinberg no sangue: positiva. Exames de L.C.R. - O primeiro exame (14-11-1958), em punção suboccipital foi hipertenso e levemente hemorrágico, sem hipercitose e reações para sífilis e cisticercose negativas. O segundo L.C.R., realizado em 20-11-1968, em punçāo suboccipital, foi límpido e incolor; 21 células por $\mathrm{mm}^{3}$ ( $80 \%$ linfócitos, $15 \%$ monócitos, $3 \%$ neutrófilos, $2 \%$ eosinófilos); $60 \mathrm{mg} \%$ de proteinas totais; reações de Pandy e Nonne fortemente positivas; reação do benjoim coloidal: 12222.12221.00000.0; reaç̃o de Takata-Ara positiva, de tipo misto; reações de Wassermann e Steinfeld negativas; reação de Weinberg fortemente positiva com $0,5 \mathrm{ml}$. Durante a internação realizou mais 8 exames de L.C.R. todos pràticamente semelhantes ao segundo.

Evolução - Foi tratada com antiedematosos (Diamox) e sulfamida (Gantrizin). Com esta terapêutica melhorou progressivamente: cessaram as alucinações visuais e a agitação psicomotora; o quadro neurológico normalizou-se; ao ter alta, em 20-12-1958, apresentava ainda amaurose bilateral. 
Caso 3 - B.S., 6 anos de idade, sexo feminino, branca, procedente de Martinópolis, São Paulo, internada em 6-11-1958 (R.G. 517.738). Passava bem até maio de 1958 quando, após "uma gripe", começou a emagrecer e a apresentar sonolência e sensação de fraqueza geral; essa sintomatologia durou 3 meses, seguindo-se 10 dias de acalmia. A seguir, a criança passou a ter diminuição da acuidade visual e periodos de agitação, intercalados com períodos de sonolência. Algum tempo antes da internação passou a ter alucinaçōes visuais em que via borboletas e outros animais( não refere quais); o inicio destas alucinações coincidiu mais ou menos, com a diminuição da visão. Antecedentes - Nada digno de nota; sem teniase pessoal ou familiar. Exame clínico-neurológico - Quadro de agitação psicomotora. O exame oftalmoscópico mostrou atrofia pós-edema das papilas, bilateralmente. Exames subsidiários - Radiografias do crânio: sinais de H.I.C.; sem calcificações. Eletrencefalograma: normal, durante o sono Exame parasitológico das fezes: ovos de Taenia sp. Reação de Weinberg no sangue: não efetuada. Exames de L.C.R. - Em 10-11-1958: Punção suboccipital; líqüido límpido e incolor; 15 células por $\mathrm{mm}^{3}(85 \%$ linfócitos, $10 \%$ monócitos, $2 \%$ neutrófilos, 3\% eosinófilos); $30 \mathrm{mg} \%$ de proteinas totais; $56 \mathrm{mg} \%$ de glicose; $680 \mathrm{mg} \%$ de cloretos; reação de Takata-Ara fortemente positiva, de tipo fluoculante; reação do benjoim coloidal: 22222.22210.00000.0; reação de Wassermann negativa; reação de Weinberg fortemente positiva com $1,0 \mathrm{ml}$. Realizou mais dois exames de L.C.R. que deram resultados semelhantes. O último L.C.R., realizado em 2-2-1959, mostrou-se normal quanto à citologia e proteínas, mas a reação de Weinberg ainda era positiva.

Evolução - Tratada com sulfamidas (Gantrizin, Lentosulfina, Sulfadiazina) e corticosteróides (Omcilon) melhorou do quadro de agitação e sonolência e, ao ter alta em 7-2-1959, apresentava apenas amaurose bilateral.

Caso 4 - J. M., 9 anos de idade, sexo feminino, branca, procedente de Conchas, São Paulo, internada em 4-4-1959 (R.G. 552.086). Passava bem até outubro de 1958, quando passou a ter cefaléia e vômitos que continuaram a se repetir em crises, com freqüência e intensidade variáveis; quando muito intensas, eram seguidas de crise Grande Mal, geralmente de curta duração. Em fevereiro 1959, passou a ter deficit progressivo de visão e, às vêzes, sensação de escurecimento das vistas, acompanhada de alucinações visuais constituídas por zoopsias, que desencadeavam verdadeiras crises de agitação psicomotora. Antecedentes - Nada digno de nota; sem teniase pessoal ou familir. Exme clinico-neurológico - o exame neurológico foi normal, mas, o exame oftalmoscópico mostrava atrofia bilateral de papila, pós-edema. Exames subsidiários - Radiografias de crânio: sinais de H.I.C.; sem calcificações. Eletrencefalograma: traçado anormalmente lento para a idade: ondas 4-5 c/s, difusas. Reação de Weinberg no sangue: positiva. Exames de L C R - Em 2-5-1959: Punção suboccipital; líqüido límpiđo e incolor; 16 células por $\mathrm{mm}^{3}$ (57\% linfócitos, $14 \%$ monócitos, $4 \%$ neutrófilos, $25 \%$ eosinófilos); $40 \mathrm{mg} \%$ de proteinas totais; reações de Pandy e Nonne-Apelt fortemente positivas; reação de Takata-Ara positiva, de tipo floculante; reação de Wassermann negativa; reação de Weinberg fortemente positiva com $0,5 \mathrm{ml}$. Realizou, durante a internação, mais 2 exames de L.C.R., cujos resultados foram pràticamente idênticos ao primeiro.

Evolução - Tratada inicialmente com sulfamida de ação lenta, corticóide e anticonvulsivos; depois, com Sulfadiazina e anticonvulsivos; teve alta em 8-6-1959 sem sintomas, a não ser a amaurose, apesar do L.C.R. ter continuado anormal por longo tempo.

Caso 5 - D. M., 8 anos de idade, sexo feminino, parda, procedente de Itápolis, São Paulo, internada em Julho de 1948 (R.G. 110.903). Passava bem até setembro ed 1947, quando passou a apresentar vômitos e deficit de visão; os vômitos se repetiram, com freqüência variável durante três meses; o defícit de visão continuou progredindo até a amaurose, em 5 meses. Em janeiro de 1948 passou a ter convulsões e alucinações visuais: as convulsões atingiam o hemicorpo esquerdo com caráter Bravais-Jacksoniano, iniciando-se na mão, sem perda de consciência; as 
alucinações visuais eram caracterizadas por visão de pessoas e animais que a assus. tavam; freqüentemente a paciente fugia procurando escapar a tais visões; essas alucinações continuaram se repetindo mesmo quando a paciente já estava comple. tamente amaurótica. A partir de fevereiro de 1948 a criança foi entrando em torpor; a partir de abril de 1948 passou a ter cefaléias. Antecedentes: Nada digno de nota: sem antecedentes pessoais ou familiares de teniase. Exame clinico-neurológico - amaurose; deficit de contactuação; carência de iniciativa muito acentuada; disfasia mista; sem paralisias nem assimetrias. O exame oftalmoscópico mostrou atrofia de papila pós-edema, bilateralmente. Exames subsidiários - Radiografias do crânio: sinais de H.I.C.; sem calcificações. Exame de L.C.R. Em 11-8-1948: Punção suboccipital; líqüido límpido e incolor; 61,3 células por $\mathrm{mm}^{3}$ (68\% linfócitos, $8 \%$ monócitos, $2 \%$ neutrófilos, $22 \%$ eosinófilos); $50 \mathrm{mg} \%$ de proteínas totais; $700 \mathrm{mg} \%$ de cloretos; $49 \mathrm{mg} \%$ de glicose; reações de Pandy e Nonne-Apelt fortemente positivas; reação de Takata-Ara positiva, de tipo floculante; reação do benjoim coloidal: 22222.22222.21000.0; reações de Wassermann e Steinfeld negativas; reação de Weinberg fortemente positiva com $1,0 \mathrm{ml}$. Pneumoventriculografia: discreta dilatação simétrica do sistema ventricular.

Evolução - Tratada com sulfamida (Albucid) e Penicilina, melhorou progressivamente: em 7-11-1948 teve alta com recuperação psíquica, persistindo, porém, a amaurose.

Caso 6 - B. A. B. S., 8 anos de idade, sexo feminino, branca, procedente de Arujá, São Paulo, internada em 27-4-1967 pela primeira vez e em 27-3-1968, pela segunda vez (R.G. 836.621). Passava bem até fevereiro de 1967, quando apresentou crise convulsiva clônica na hemicorpo direito, que durou mais ou menos uma hora, sem sequielas aparentes imediatas; crise semelhante ocorreu 1 mês após. Desde então passou a ter alucinações visuais que duravam 5 a 10 minutos e ocorriam 5 a 6 vêzes ao dia, em vigília ou durante o sono; nessas crises via animais, ou os vizinhos atirando pedras e animais contra o telhado de sua casa; estas alucinações deixavam a paciente agitada e amedrontada e então, ela corria para os familiares à procura de proteção. No intervalo entre as crises apresentava comportamento normal, inicialmente; porém, com o passar do tempo foi modificando o comportamento. Antecedentes - Desde março de 1967, passou a eliminar proglótides de tênia. Sem teníase entre os familiares. Exame clínico-neurológico Quadro psíquico caracterizado principalmente pelas alucinações visuais, entremeadas de periodos de apatia. Exame neurológico normal e a oftalmoscopia foi normal. Exames subsidiários - Radiografias de crânio: normal. Eletrencefalograma: disritmia difusa contínua, constituida por ondas lentas delta e teta de voltagem média e elevada; foco irritativo (espiculas e ondas "sharp") na região occipital esquerda. Pneumencefalograma: normal. Exames de L.C.R. - Eletroforese das proteinas: aumento das gamaglobulinas. Em 17-4-1967 punção suboccipital; liqüido levemente turvo e incolor; límpido e incolor após centrifugação; 257 células por $\mathrm{mm}^{3}$ (58\% linfócitos, 9\% monócitos, $2 \%$ neutrófilos, $31 \%$ eosinófilos); $60 \mathrm{mg} \%$ de proteínas totais; $710 \mathrm{mg} \%$ de cloretos; $44 \mathrm{mg} \%$ de glicose; reacōes de Pandy e Nonne-Apelt positivas; reação de Takata-Ara positiva, de tipo floculante; reações de Wassermann e Steinfeld negativas; reação de Weinberg positiva com $0,5 \mathrm{ml}$. Durante o periodo das duas internaçōes ainda realizou mais $\mathbf{5}$ exames de L.C.R., cujos resultados foram semelhantes, embora a pleocitose tivesse variado de 40 a 341 células por $\mathrm{mm}^{3}$.

Evolucão - Tratada com sulfadiazina, corticóides, Daraprin e anticonvulsivos; porém, o quadro psíquico se agravou, obrigando a transferência da paciente para a Clínica Psiquiátrica, onde ficou internada até 27-3-1968, quando voltou à Clínica Neurológica para reavaliação. Apresentava acentuado retardo mental; estava completamente alheiada ao meio ambiente; quanto ao exame neurológico, revelava hipertonia dos flexores dos membros superiores, mais acentuada à esquerda e tinha tremores à movimentação ativa. Nessas condições foi enviada para instituição adequada, em 15-4-1968. 


\section{COM ENTÃ R IOS}

Esta série de pacientes oferece alguns aspectos a serem analisados, inclusive a curiosa coincidência de todos serem do sexo feminino, embora a incidência total de neurocisticercose em crianças revele uma preponderância $(54 \%)$ para o sexo masculino (Canelas, 1962). O quadro psiquiátrico ofereceu alguns aspectos constantes: tôdas estas meninas apresentavam um quadro de agitação psicomotora, com períodos de exacerbação, em geral coincidentes com alucinações visuais terrorificas sob a forma de zoopsias. Estas alucinações visuais eram especialmente dramáticas em 5 dos casos em que havia grande deficit visual e mesmo amaurose total; as pacientes, a despeito de reconhecerem a falta de visão, gritavam assustadas afirmando ver bichos avançando sôbre elas.

Nenhum dos casos permitiu exame psiquiátrico ou psicológico mais detalhado durante a fase aguda, em virtude da agitação psicomotora. A evolução foi relativamente satisfatória, tendo em vista o mau prognóstico da neurocisticercose. Assim, é que, após o tratamento de rotina (sulfamidicos, corticóides, anticonvulsivos e sedativos), apenas o caso 6 continuou com quadro psiquiátrico grave, a ponto de precisar ser recolhido à uma instituição especializada. Em todos os demais, os sintomas psiquiátricos registrados por ocasião da internação, desapareceram.

Parece-nos importante o resultado obtido com a terapêutica; embora o número de casos seja pequeno, a remissão do quadro clínico em 5 dos 6 pacientes merece registro. Aguardamos a ampliação da casuística bem como a observação de casos semelhantes por outros autores para a confirmação dos resultados aqui registrados. Desejamos deixar assinalado que na literatura que pudemos compulsar não verificamos o registro de casos semelhantes aos aqui apresentados.

\section{R E S M O}

Os autores apresentam as observações clínicas de 6 casos de neurocisticercose em crianças, tôdas do sexo feminino. De um total de 54 casos de neurocisticercose em crianças, destacaram êstes 6 nos quais havia, de comum, o fato das pacientes apresentarem intensa agitação psicomotora, com alucinações visuais terroríficas (zoopsias), sendo que 5 destas crianças haviam perdido totalmente a visão, o que tornava o quadro ainda mais dramático. As características clínicas dêstes casos são relatadas sendo destacada a evolução relativamente satisfatória, tendo em vista o mau prognóstico da neurocisticercose.

S U M M A R Y

\section{Psychic disturbances in children with neurocysticercosis}

Six cases of neurocysticercosis in children are reported. These 6 patients were selected from a total number of 54 cases, in view of their particular symptomatology, represented by terrifying visual hallucinations 
(zoopsias) and psichic disturbances. Five of the patients also had a total loss of sight. The clinical characteristics of the patients are reported. The relatively satisfactory response to treatment in 5 cases is commented.

\section{R E F E R E N C I A S}

1. ALMEIDA, G. M.; PEREIRA, W. C. \& FACURE, N. O. - Ventrículo-auriculostomia nos bloqueios ao trânsito do líquido cefalorraqueano na cisticercose encefálica. Arq. Neuro-Psiquiat. (São Paulo) 24:169, 1966.

2. BRotTo, W. - Aspectos neurológiros da cisticercose. Arq. Neuro-Psiquiat. (São Paulo) 5:258, 1947.

3. CaEtano Silva Jr., J. A. - Cisticercose cerebral. Resultados obtidos com o tratamento sulfamídico. Arq. Neuro-Psiquiat. 9:43, 1951.

4. CANElAS, H. - Neurocisticercose: incidência, diagnóstico e formas clínicas. Arq. Neuro-Psiquiat. (São Paulo) 20:1, 1962.

5. CANELAS, H. \& RICCIARDI CRUZ, O. - Formas clinicas pouco freqüentes da neurocisticercose: Formas hemiplégicas. Arq. Neuro-Psiquiat. (São Paulo) 20:89, 1962.

6. CANElAS, H. M.; RICCIARDI CRUZ, O. \& TENUTO, R. A. - Formas clinicas pouco freqüentes da neurocisticercose; Formas do ângulo ponto-cerebelar. Arq. Neuro-Psiquiat. (São Paulo) 20:102, 1962.

7. CANElas, H. M.; RICCIARDI CRUZ, O. \& ESCAlANTE, O. A. D. - Cysticercosis of the nervous system: less frequent clinical forms: spinal cord forms. Arq. Neuro-Psiquiat. (São Paulo) 21:77, 1963.

8. FORJAZ, S. V. \& Martinez, M. - Formas obstrutivas da neurocisticersose ventricular. Arq. Neuro-Psiquiat. (São Paulo) 19:16, 1961.

9. LONGO, P. W.; PUPO, P. P.; ZUKERMIAN, E.; LONGO, R. H.; MOREIRA, M. H. F. R.; JORDY, C.; LIMA, J. G. C. \& ZORLINI, G. - Asepctos eletrencefalográficos da cisticercose encefálica Arq. Neuro-Psiquiat. (São Paulo) 17: 357, 1959.

10. RICCIARDI CRUZ, O. - Compressão radiculomedular por cisticerco: registro de dois casos com tratamento cirúrgico. Arq. Neuro-Psiquiat. (São Paulo) 19:231, 1961 .

11. SIlveIRA, A.; ROBORTElla, M. \& MAFFEI, W. E. - Quadro clínico do lobo orbitário com crises cerebelares: cisticercose racemosa do ângulo pontocerebelar. Arq. Neuro-Psiquiat. (São Paulo) 18:152, 1960.

12. SPINA-FRANÇA, A. - Valor do exame eletroforético das proteínas do líquido cefalorraqueano na cisticercose do sistema nervoso central. Arq. Neuro-Psiquiat. (São Paulo) 18:301, 1960.

13. SPINA-FRANÇA, A. - Síndrome liquórica da neurocisticercose. Arq. NeuroPsiquiat. (São Paulo) 19:307, 1961.

14. SPINA-FRANÇA, A. - Aspectos biológicos da neurocisticercose: alterações do líquido cefalorraqueano. Arq. Neuro-Psiquiat. 20:17, 1962. 